Microbes and Environments

Vol. 14, No. 4, $201-208,1999$

\title{
Phenotypic Characterization of a Mutant of Burkholderia cepacia MRT11 Defective in Rhizosphere Competence
}

\author{
Koki Toyota ${ }^{*}$, Chikayo Hiraiwa (NoJiri) ${ }^{1}$ and Makoto Kimura \\ Laboratory of Soil Biology and Chemistry, Graduate School of Bioagricultural Sciences, Nagoya \\ University, Nagoya 464-8601, Japan \\ ${ }^{1}$ presently at Criminal Investigation Laboratory, Aichi Prefectural Police HQ., Nagoya 460-0001, \\ Japan
}

(Received May 26, 1999-Accepted August 13, 1999)

\begin{abstract}
A mutant (RCD1) defective in rhizosphere competence of Burkholderia cepacia MRT11, an effective root colonizer of radish, was isolated by successive single colony transfers. The ability of RCD1 to colonize radish root was reduced to about one $\%$ of that of the wild type strain MRT11. The properties considered to be involved in the colonization of the roots were compared between the two strains. There were no significant differences between the two strains in motility, chemotactic response to root exudates, cell surface hydrophobicity, adherence to roots, and in vitro antibiosis to fungal pathogens. There were also not significant differences in the growth of most media used in this study, such as nutrient broth, minimum medium with glucose, galactose, or casamino acids as the sole carbon source. However, the growth of MRT11 in radish root exudate was greater than that of RCD1, suggesting that the ability to utilize root exudates might be responsible for part of the rhizosphere competence of $B$. cepacia MRT11. The properties that were impaired in RCD1 are further discussed in relation to the utilization of root exudate.
\end{abstract}

Key words: rhizosphere competence, root exudate, competition, radish

Although the development of biocontrol agents of soil-borne plant pathogens was attempted by many investigators, there have been few commercially successful examples in the field. As Deacon' ${ }^{6}$ pointed out, most attempts to develop biological control agents have failed because the organisms were selected for in vitro antagonism, but were ecologically unsuited to the in situ environment of the pathogens. One of the major constraints is the inconsistent colonization of roots by biocontrol agents, where the agents presumably protect plants from pathogens. Therefore, knowledge about factors that contribute to root colonization is required.

\footnotetext{
* Corresponding author; E-mail: ktoyota@nuagr1.agr. nagoya-u.ac.jp
}

Root colonization is defined as the process whereby introduced microorganisms become distributed along roots growing in nonsterile soil, multiply and survive for several weeks in the presence of the indigenous soil microflora ${ }^{30)}$. Root colonization involves two phases: Phase I is the attachment to roots, and Phase II is the multiplication on roots ${ }^{10)}$. Rhizosphere competence describes the relative root-colonizing ability of a rhizobacterium ${ }^{31)}$.

According to Weller ${ }^{30)}$, and Weller and Thomashow ${ }^{31)}$, bacterial traits that contribute to rhizosphere competence are mostly unknown, but some that may be important are categorized into three classes. Class I involves cell surface polysaccharides ${ }^{3,5,25)}$, cell surface hydrophobicity ${ }^{4}$, fimbriae $^{29)}$, flagella ${ }^{8)}$ and chemotaxis toward seed or 
root exudates ${ }^{9,21)}$. These factors are important in Phase I of root colonization. Class II involves growth rate ${ }^{18,23)}$ and the ability to utilize complex carbohydrates ${ }^{1,2,11,18)}$, which are important in Phase II. The abilities to synthesize growth factors like some kinds of amino acids or vitamins were also important in Phase $\mathrm{II}^{22,23,24)}$. In some cases; the production of antibiotic contributes to rhizosphere competence ${ }^{17)}$. Class III involves osmotolerance, which is necessary for survival.

Burkholderia cepacia MRT11 was originally isolated from the roots of radish grown in a disease-suppressive soil and was considered to be one of the entities suppressing the growth of Fusarium oxysporum f. sp. raphani on the roots ${ }^{26}$. B. cepacia MRT11, inoculated as a seed coating, colonized roots of radish grown in a nonsterile soil at about $10^{7} \mathrm{cfu} \mathrm{g}^{-1}$ root $^{27)}$, which qualified it as rhizosphere competent. A mutant of $B$. cepacia MRT11 defective in rhizosphere competence was naturally isolated by successive single colony transfers on $10^{-1}$ strength nutrient agar (1/10 NA: Eiken Chemical Co. Ltd.). This study investigated properties considered involved in the successful colonization of roots by comparing the wild type strain and its mutant.

\section{Materials and Methods}

\section{Soil and strains used}

Miura soil (Kanagawa Pref., Japan), which is suppressive to Fusarium-wilt of radish ${ }^{13,28)}$, was used. The properties of the soil were reported previously by Toyota $e t a l .{ }^{26}$. The soil was sieved $(2 \mathrm{~mm})$ and kept at $4^{\circ} \mathrm{C}$ before use.

B. cepacia MRT11 and its rhizosphere-competence defective mutant, designated RCD1, were used. A spontaneous mutant of RCD1 resistant to rifampicin $\left(100 \mu \mathrm{g} \mathrm{ml}^{-1}\right)$, designated as RCD1Rif1, was also used. MRT11, RCD1 and RCD1Rif1 were intrinsically resistant to ampicillin (Ap; $50 \mu \mathrm{g} \mathrm{ml}^{-1}$ ) and tetracycline (Tc: $12.5 \mu \mathrm{g} \mathrm{ml}^{-1}$ ) and showed a colony morphology characteristic of $B$. cepacia with a creamy and dry surface.

Bacterial inocula were prepared by overnight cul-

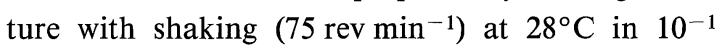

strength nutrient broth (1/10 NB: Eiken Chemical Co. Ltd.)

Colonization of radish roots by B. cepacia MRT11 and $R C D 1$

Radish seeds ( $R$. sativus L.) were surface-sterilized in $70 \%$ ethanol for $2 \mathrm{~min}$ and incubated on 1/10 NA at $28^{\circ} \mathrm{C}$. One-day-old seeds were immersed for $30 \mathrm{~min}$ in $10 \mathrm{ml}$ of a suspension containing $10^{7} \mathrm{cfu} \mathrm{ml}^{-1}$ of MRT11 or RCD1 that were grown in $1 / 10$ NB for 24 $\mathrm{h}$ at $28^{\circ} \mathrm{C}$ with shaking, washed with $20 \mathrm{mM}$ sodium phosphate buffer ( $\mathrm{pH}$ 7.0: $\mathrm{PB}$ ), and resuspended in $\mathrm{PB}$. The radish seeds were then rinsed in sterile distilled water (SDW) and grown in Miura soil, the water content of which had been adjusted to $60 \%$ of its maximum water-holding capacity, for $10 \mathrm{~d}$ at room temperature $\left(15\right.$ to $\left.20^{\circ} \mathrm{C}\right)$. The roots were removed from soil and washed in SDW to remove adhering soil material. Populations of inoculated bacteria on the roots were counted on 1/10 NA amended with Ap (50 $\left.\mu \mathrm{g} \mathrm{ml}^{-1}\right)$ and Tc $\left(12.5 \mu \mathrm{g} \mathrm{ml}^{-1}\right)$ after the roots had been macerated in a sterile mortar and pestle. Although indigenous bacteria resistant to the two antibiotics were present on the roots at a density of $10^{4} \mathrm{cfu} \mathrm{g}^{-1}$ root, there were no colonies on the selective medium that showed the colony morphology of MRT11, which enabled the detection of the inoculated bacteria. Four whole root systems were separately processed for each inoculum and three replicate plates were used for each dilution. The experiment was repeated twice.

Motility, chemotaxis, cell surface hydrophobicity, adherence to radish roots and antibiosis

Motility and chemotaxis to root exudate was assessed by the method of Scher et al. ${ }^{21)}$. Bacteria from a 48-h culture on 1/10 NA were spotted onto soft agar $(0.2 \%)$ containing $1 / 10 \mathrm{NB}$ or root exudate [10\% $(\mathrm{v} / \mathrm{v})]$, the collection method of which is described below, for the examinations of motility and chemotaxis, respectively. The agar plates were kept at $28^{\circ} \mathrm{C}$ and the diameters of the resulting swarms were periodically determined. The experiments were done in triplicate. Root exudate was prepared as follows. Radish seeds, surface-sterilized in 70\% ethanol for 2 
min and preemerged on $1 / 10 \mathrm{NA}$ at $28^{\circ} \mathrm{C}$ for $1 \mathrm{~d}$, were grown in sterile sea sand at $100 \%$ water-holding capacity in an aseptic plastic cup (AgriPot ${ }^{\mathrm{R}}$; KIRIN Beer Co. Ltd) at root temperature $\left(15-20^{\circ} \mathrm{C}\right)$. After 10 days, root exudate from $1.6 \mathrm{~g}$ of roots was collected by centrifugation and filter-sterilization $(0.2 \mu \mathrm{m})$. A dissolved organic carbon of $64.9 \mathrm{mg} \mathrm{g}^{-1}$ of dry root was obtained by this treatment. The concentration of the root exudate finally prepared was $86 \mu \mathrm{g}-\mathrm{C} \mathrm{ml}^{-1}$ (Shimazu, TOC-500). The major components were $60 \%$ neutral sugars (determined by HPLC), 11\% acidic sugars (by colorimetric method ${ }^{15)}$ ) and 3\% amino acids (by ninhydrin reaction). The sugars were comprised of $61 \%$ galactose, $19 \%$ glucose and others (by HPLC), and were exclusively oligo- or polymers, not monosaccharides.

The relative hydrophobicity of the surfaces of bacterial cells was determined by observing the change in absorbance of cell suspensions after partitioning in $n$-hexadecane ${ }^{20)}$. Bacterial cells in log and stationary phases were used. Test tubes containing $1 \mathrm{ml}$ of bacterial suspension and $200 \mu$ l of $n$-hexadecane were agitated on a vortex for $2 \mathrm{~min}$. The aqueous and organic phases were allowed to separate for $15 \mathrm{~min}$, and the absorbance of the aqueous phase was measured at $660 \mathrm{~nm}$. The experiment was conducted in duplicate and repeated twice.

The density of bacterial cells suspended in PB were adjusted turbidimetrically to $10^{7} \mathrm{cfu} \mathrm{m}^{-1}$. The adherence assay was initiated by transferring a piece (each $2 \mathrm{~cm}$ in length) of 10-day-old radish root into a test tube containing $1 \mathrm{ml}$ of the bacterial suspension. After $60 \mathrm{~min}$ of still incubation at $25^{\circ} \mathrm{C}$, the roots were removed and rinsed three times in fresh PB. The bacterial populations were determined by the dilution plate method after homogenization of the roots in a sterile mortar and pestle. Five root pieces were used.

In vitro antibiosis of bacteria against Fusarium oxysporum f. sp. raphani and Rhizoctonia solani was measured on potato dextrose agar (PDA: Eiken Chemical Co. Ltd.). Each bacterium and a mycelial plug ( $5 \mathrm{~mm}$ in diameter) of each pathogen were placed at the edge and the center, respectively, of a 6-cm Petri plate containing PDA. The plates were incubated for seven days at $28^{\circ} \mathrm{C}$ and zones of inhibition were measured.

\section{Growth in different media}

Bacteria were grown with shaking $\left(75 \mathrm{rev} \mathrm{min}^{-1}\right)$ at $28^{\circ} \mathrm{C}$ and the growth rates in a full-strength nutrient broth (NB: Eiken chemical Co. Ltd.), $10^{-1}$ strength NB (1/10 NB), $10^{-2}$ strength NB (1/100 NB), $10^{-3}$ strength $\mathrm{NB}(1 / 1000 \mathrm{NB})$ and glucose or galactose medium $\left(0.1 \% \mathrm{KH}_{2} \mathrm{PO}_{4}, 0.05 \% \mathrm{KCl}, 0.05 \% \mathrm{MgSO}_{4} \cdot 7\right.$ $\mathrm{H}_{2} \mathrm{O}, 0.1 \% \mathrm{NH}_{4} \mathrm{NO}_{3}, 0.5 \%$ carbon source, $\mathrm{pH} 6.8$ ) were determined tubidimetrically at $660 \mathrm{~nm}(\mathrm{NB}, 1 / 10$ $\mathrm{NB}$, glucose and galactose media) or by periodic enumerations of cfu by the dilution plate method $(1 / 100 \mathrm{NB}$ and $1 / 1000 \mathrm{NB})$.

Maximum population in minimum medium $(0.1 \%$ $\mathrm{KH}_{2} \mathrm{PO}_{4}, 0.05 \% \mathrm{KCl}, 0.05 \% \mathrm{MgSO}_{4} \cdot 7 \mathrm{H}_{2} \mathrm{O}, 0.1 \%$ $\mathrm{NH}_{4} \mathrm{NO}_{3}, 0.2 \%$ carbon source, $\mathrm{pH} 6.8$ ) with various kinds of organic matter (gum arabic (Sigma), xylan, raffinose, polygalacturonic acid, casamino acids) as a sole carbon source were measured by inoculating $10^{4}$ cfu of MRT11 or RCD1 into $1 \mathrm{ml}$ of the medium and incubating for 2 to 5 days at $28^{\circ} \mathrm{C}$. Counts were made every $24 \mathrm{~h}$ during the period. Each test was conducted in duplicate and repeated twice.

Substrate utilization ability of MRT11 and RCD1 was examined using Biolog GN plates (Biolog, Inc., Hayward, CA) with the manufacture's instruction. Two replica plates were used for each strain and repeated twice.

\section{Competitive growth of MRT11 and RCDIRif1}

MRT11 and RCD1Rif1 were simultaneously inoculated into $1 / 10 \mathrm{NB}$ and root exudate at an initial density of $10^{4} \mathrm{cfu}$ each strain and incubated for 2 and 3 days, respectively, at $28^{\circ} \mathrm{C}$. The numbers of MRT11 and RCD1Rif1 were determined on 1/10 NA. About 100 colonies that appeared on $1 / 10 \mathrm{NA}$ were transferred onto 1/10 NA with rifampicin $\left(100 \mu \mathrm{g} \mathrm{ml}^{-1}\right)$ for separating RCD1Rif1 from MRT11. Two test tubes were used for each medium and repeated once.

\section{Statistical analysis}

The data were processed by standard analysis of variance and Student's t-test. 


\section{Results}

Colonization of radish roots by B. cepacia MRT11 and $R C D 1$

B. cepacia MRT11 was detected on radish roots at a density of $1.4 \pm 0.1 \times 10^{7} \mathrm{cfu} \mathrm{g}^{-1}$ of root, which was $6.6 \%$ of the total bacteria detected on the roots. In contrast, RCD1 and RCD1 Rif1 colonized radish roots at a density of $1.7 \pm 0.9 \times 10^{5}$ and $3.7 \pm 2.1 \times 10^{5}$, respectively, cfu $\mathrm{g}^{-1}$ of root and the difference in colonization between MRT11 and RCD1 or RCD1Rif1 was highly significant $(\mathrm{P}<0.001)$.

Motility, chemotaxis, cell surface hydrophobicity, attachment to radish roots and antibiosis

There were no significant differences in motility in $1 / 10$ NA and in the chemotactic response to root exudate between MRT11 and RCD1 (Fig. 1A, B). Adherence $(\%)$ of MRT11 and RCD1 cells to $n$-hexadecane was $41 \pm 4 \%$ and $47 \pm 4 \%$ in the exponential phase and $80 \pm 9 \%$ and $77 \pm 9 \%$, respectively, in the stationary phase, showing no significant difference in cell surface hydrophobicity between the two strains. There was also not a significant difference between the two strains in their attachment to radish roots: MRT11 and RCD1 attached at a density of $6.83 \pm 2.17 \times 10^{4}$ and $1.08 \pm 0.62 \times 10^{5}$, respectively, $\mathrm{cfu} \mathrm{cm}^{-1}$ of root. MRT11 and RCD1 formed a similar size of inhibition zone on PDA against Rhizoctonia solani and Fusarium oxysporum f. sp. raphani.

\section{Growth in different media}

There were no significant differences between MRT11 and RCD1 in their growth rates and maximum population in NB, $1 / 10 \mathrm{NB}, 1 / 100 \mathrm{NB}, 1 / 1000 \mathrm{NB}$ and minimum media with glucose or galactose as the sole carbon source (Table 1). The maximum population was also not significant $(\mathrm{P}<0.05)$ between the two strains in minimum medium with other possible components of root exudate, i.e., galacturonic acid, raffinose, gum arabic, xylan and casamino acids, whereas the maximum population of MRT11 in root exudate and polygalacturonic acid medium was significantly $(\mathrm{P}<0.05)$ higher than that of RCD1 (Table 2).
RCD1 utilized all of the substrates in a Biolog GN plate that MRT11 utilized. Although the substrate utilization pattern differed to some extent between the two strains, there was no consistent tendency ob-
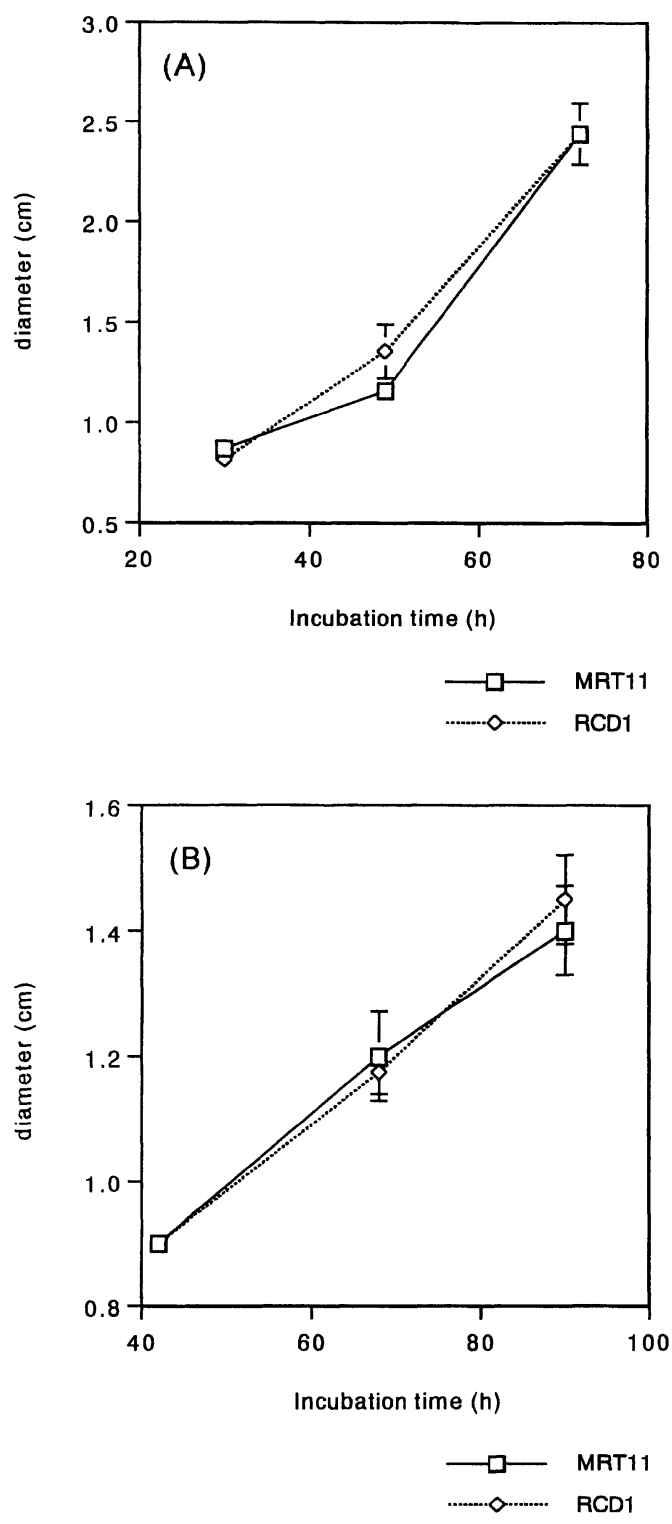

Fig. 1. Motility (A) and chemotactic responce to root exudate (B) of Burkholderia cepacia MRT11 and RCD1. The diameters of swarms in NB or root exudate containing $0.2 \%$ agar were periodically determined. Mean values \pm SD are presented. 
Table 1. Generation times of MRT11 and RCD1 in different media.

\begin{tabular}{lcc}
\hline & MRT11 (h) & RCD1 (h) \\
\hline NB & $1.3 \pm 0.1$ & $1.4 \pm 0.0$ \\
$1 / 10 \mathrm{NB}$ & $1.3 \pm 0.1$ & $1.4 \pm 0.0$ \\
$1 / 100 \mathrm{NB}$ & $1.5 \pm 0.0$ & $1.5 \pm 0.1$ \\
$1 / 1000 \mathrm{NB}$ & $1.7 \pm 0.0$ & $1.6 \pm 0.0$ \\
Glucose & $3.0 \pm 0.1$ & $2.9 \pm 0.2$ \\
Galactose & $5.0 \pm 0.2$ & $5.1 \pm 0.2$ \\
\hline
\end{tabular}

served between repeated experiments.

\section{Competitive growth of MRT11 and RCDIRif1 in} $1 / 10 N B$ and root exudate

When MRT11 and RCD1Rif1 were co-inoculated at an initial density of $10^{4} \mathrm{cfu}$ each in $1 / 10 \mathrm{NB}$ and root exudate, total population reached $1.3 \times 10^{9} \mathrm{ml}^{-1}$ in $1 / 10 \mathrm{NB}$ and $2.9 \times 10^{7} \mathrm{ml}^{-1}$ in root exudate after 2 and 3 days incubation, respectively, during which the initial ratio of RCD1Rif1 decreased significantly $(\mathrm{P}<0.05)$ (Fig. 2).

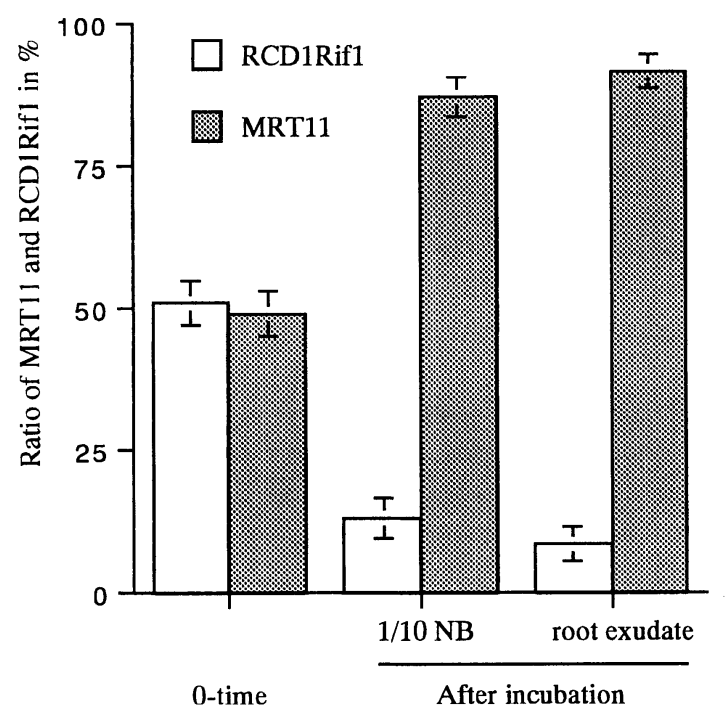

Fig. 2. Competitive growth of MRT11 and RCD1Rif1 in 1/10 $\mathrm{NB}$ and root exudate. Mean values $\pm \mathrm{SD}$ are presented.

\section{Discussion}

In the present study, the properties considered responsible for rhizosphere competence were compared between $B$. cepacia MRT11 and its

Table 2. Maximum populations of MRT11 and RCD1 in different media.

\begin{tabular}{|c|c|c|}
\hline & MRT11 (cfu m-1) & $\mathrm{RCD} 1\left(\mathrm{cfu} \mathrm{m}^{-1}\right)$ \\
\hline \multicolumn{3}{|l|}{ Complex media } \\
\hline NB & $4.2 \pm 0.3 \times 10^{9}$ & $4.6 \pm 0.5 \times 10^{9}$ \\
\hline $1 / 10 \mathrm{NB}$ & $1.5 \pm 0.1 \times 10^{9}$ & $1.2 \pm 0.3 \times 10^{9}$ \\
\hline $1 / 100 \mathrm{NB}$ & $1.0 \pm 0.1 \times 10^{8}$ & $9.6 \pm 0.7 \times 10^{7}$ \\
\hline $1 / 1000 \mathrm{NB}$ & $1.2 \pm 0.2 \times 10^{7}$ & $1.1 \pm 0.2 \times 10^{7}$ \\
\hline Root exudate & $4.1 \pm 0.8 \times 10^{7}$ & $2.5 \pm 0.3 \times 10^{7 *}$ \\
\hline \multicolumn{3}{|c|}{ Minimum media with the sole carbon source } \\
\hline Glucose & $1.1 \pm 0.4 \times 10^{8}$ & $1.5 \pm 0.4 \times 10^{8}$ \\
\hline Galactose & $1.8 \pm 0.4 \times 10^{8}$ & $2.1 \pm 0.4 \times 10^{8}$ \\
\hline Galacturonic acid & $1.5 \pm 0.1 \times 10^{8}$ & $1.8 \pm 0.8 \times 10^{8}$ \\
\hline Raffinose & $3.2 \pm 1.1 \times 10^{7}$ & $3.0 \pm 1.1 \times 10^{7}$ \\
\hline Casamino acids & $3.9 \pm 1.3 \times 10^{8}$ & $3.4 \pm 0.7 \times 10^{8}$ \\
\hline Gum arabic & $2.0 \pm 0.4 \times 10^{7}$ & $2.4 \pm 0.9 \times 10^{7}$ \\
\hline Xylan & $1.1 \pm 0.1 \times 10^{8}$ & $8.7 \pm 1.1 \times 10^{7}$ \\
\hline Polygalacturonic acid & $1.5 \pm 0.2 \times 10^{8}$ & $1.2 \pm 0.1 \times 10^{8 *}$ \\
\hline
\end{tabular}

*: significantly $(\mathrm{P}<0.05)$ different from MRT11 
rhizosphere-competence defective mutant (RCD1), obtained by successive colony transfers. Both strains grew in the minimum medium with various kinds of carbon sources and showed in vitro antibiosis against fungal pathogens, suggesting that this mutant is neither auxotrophic nor pleiotropic. Simons et al. ${ }^{23,24)}$ have reported that auxotrophic mutants defective in the synthesis of amino acids or vitamins showed inferior rhizosphere competence compared to the parental strains. A mutant with a reduced biological control ability was pleiotropic and defective in the production of hydrogen cyanide, 2,4-diacetylphloroglucinol and pyoluteorin, albeit possessing a similar degree of rhizosphere competence ${ }^{14)}$.

There were no significant differences between the two strains in almost all the tests in this study. The only difference observed was the maximum population in root exudate (Table 2): the maximum population of RCD1 in root exudate was ca. $40 \%$ lower than that of MRT11, suggesting that RCD1 had lost the ability to assimilate some constituents of root exudate. The maximum population of RCD1 in the polygalacturonic acid medium was significantly $(\mathrm{P}<0.05)$ lower than that of MRT11, while the maximum population of RCD1 in the medium of galacturonic acid, the constituent of polygalacturonic acid, did not differ from that of MRT11 (Table 2). This result suggests that the ability to assimilate polymeric galacturonic acid effectively might be responsible for a part of the reduced ability of RCD1 to grow in root exudate. Polymeric galacturonic acid was determined to be a part $(11 \%)$ of the root exudate in this study and according to Oades ${ }^{19)}$, pectic substances are contained in insoluble root exudate (mucigel) as major components. The ability to utilize root exudate has been indicated to be significant in the process of root colonization by many researchers $6,12,15,30,31)$. There have been, however, few reports that experimentally confirmed its importance. Ahmad and Baker ${ }^{1,2}$ reported that mutants of Trichoderma harzianum with increased cellulase production had a greater competitive saprophytic ability and had greater rhizosphere competence compared with the wild type. Ikeda et $a l .{ }^{11)}$ reported that extracellular pectinase production might play a role in the rhizosphere competence of
Burkholderia (Ralstonia) pickettii MSP3Rif. Our study also indicated that the ability to utilize root exudate might be responsible for a significant part of the rhizosphere competence of a bacterial strain. Indeed, the ratio of RCD1Rif1 markedly decreased after incubation when RCD1Rif1 and MRT11 were co-inoculated into root exudate (Fig. 2).

RCD1Rif1 was impaired in competitive growth not only in root exudate but also in $1 / 10 \mathrm{NB}$, even though RCD1 displayed similar growth rate and maximum population in $1 / 10 \mathrm{NB}$ to MRT11 when separately inoculated. Therefore, it was difficult to explain the reduced rhizosphere competence of RCD1 only from the reduced ability to utilize root exudate. Dekkers et $a l .{ }^{7)}$ studied colonization-defective mutants of Pseudomonas fluorescens WCS365 and found that some of the mutants had an impaired ability to synthesize the O-antigen of lipopolysaccharide and showed poorer competitive growth in a medium. Thus, impairment of competitive growth may also be involved in the reduced rhizosphere competence of RCD1. Further molecular and biochemical approaches are necessary to provide further information on the rhizosphere competence of Burkholderia cepacia MRT11.

\section{Acknowledgment}

We thank Dr. S. Fujiwara for assistance in soil sampling and Dr. H. Tanaka for the analysis of sugars.

\section{References}

1) Ahmad, J.S. and R. Baker. 1987. Rhizosphere competence of Trichoderma harzianum. Phytopathol. 77: 182-189.

2) Ahmad, J.S. and R. Baker. 1987. Competitive saprophytic ability and cellulolytic activity of rhizosphere-competent mutants of Trichoderma harzianum. Phytopathol. 77: 358-362.

3) Anderson, A.J., P. Habibzadegah-Tari and C.S. Tepper. 1988. Molecular studies on the role of a root surface agglutinin in adherence and colonization by Pseudomonas putida. Appl. Environ. Microbiol. 54: $375-380$

4) Araujo, R.S., E.A. Robleto and J. Handelsman. 1994. A hydrophobic mutant of Rhizobium etli altered in nodulation competitiveness and growth in 
the rhizosphere. Appl. Environ. Microbiol. 60: 1430-1436.

5) Chao, W.-L., R.-K. Li and W.-T. Chang. 1988. Effect of root agglutinin of microbial activities in the rhizosphere. Appl. Environ. Microbiol. 54: 1838-1841.

6) Deacon, J.W. 1991. Significance of ecology in the development of biocontrol agents against soil-borne plant pathogens. Biocont. Sci. Technol. 1: 5-20.

7) Dekkers, L.C., A.J. van der Bij, I.H.M. Mulders, C.C. Phoelich, R.A.R. Wentwoord, D.C.M. Glandorf, C.A. Wijffelman and B.J.J. Lugtenberg. 1998. Role of the O-antigen of lipopolysaccharide, and possible roles of growth rate and NADH:ubiquinone oxidoreductase (nuo) in competitive tomato root-tip colonization by Pseudomonas fluorescens WCS365. Mol. Plant-Microbe Interact. 11: 763-771.

8) De Weger, L.A., C.I.M. van der Vlugt, A.H.M. Wijfjes, P.A.H.M. Bakker, B. Schippers and B. Lugtenberg. 1987. Flagella of a plant-growthstimulating Pseudomonas fluorescens strain are required for colonization of potato roots. J. Bacteriol. 169: $27691-2773$.

9) Heinrich, D. and D. Hess. 1985. Chemotactic attraction of Azospirillum lipoferum by wheat roots and characterization of some attractants. Can. J. Microbiol. 31: 26-31.

10) Howie, W.J., R.J. Cook and D.M. Weller. 1987. Effects of soil matric potential and cell motility on wheat root colonization by fluorescent psedomonads suppressive to take-all. Phytopathol. 77: 286-292.

11) Ikeda, K., K. Toyota and M. Kimura. 1998. Role of extracellular pectinase production in the rhizoplane competence of a rhizobacterium Burkholderia pickettii MSP3. Soil Biol. Biochem. 30: 323-329.

12) Kluepfel, D.A. 1993. The behavior and tracking of bacteria in the rhizosphere. Ann. Rev. Phytopathol. 31: 441-472.

13) Komada, H. and N. Kobayashi. 1983. Effect of various organic amendmedts on the disease incidence of radish yellows, caused by Fusarium oxysporum $\mathrm{f}$. sp. raphani, in different soil types. Proc. Kanto-Tosan Plant Prot. Soc. 30: 69-72.

14) Laville, J., C. Voisard, C. Keel, M. Maurhofer, G. Defago and D. Haas. 1992. Global control in Pseudomonas fluorescens mediating antibiotic synthesis and suppression of black root rot of tobacco. Proc. Natl. Acad. Sci. USA. 89: 1562-1566.

15) Lynch, D.L., E.E. Hearns and L.J. Jr. Cotnoir. 1957. The determination of polyuronides in soils with carbazole. Soil Sci. Soc. Amer. Proc. 21: 160-162.

16) Mazzola, M. and R.J. Cook. 1991. Effects of fungal root pathogens on the population dynamics of biocontrol strains of fluorescent pseudomonads in the wheat rhizosphere. Appl. Environ. Microbiol. 57: 2171-2178.

17) Mazzola, M., R.J. Cook, L.S. Thomashow, D.M. Weller and L.S. Pierson III. 1992. Contribution of phenazine antibiotic biosynthesis to the ecological competence of fluorescent pseudomonads in soil habitats. Appl. Environ. Microbiol. 58: 2616-2624.

18) Parke, J.L. Root colonization by indigenous and introduced microorganisms, in "The rhizosphere and plant growth", eds by D.L. Keister and P.B. Cregan. Kluwer Academic Publishers, Dordrecht, 1991, pp.33-42.

19) Oades, J.M. 1978. Mucilages at the root surface. J. Soil Sci. 29: 1-16.

20) Rosenberg, M., D. Gutnick and E. Rosenberg. 1980. Adherence of bacteria to hydrocarbons: a simple method for measuring cell-surface hydrophobicity. FEMS Microbiol. Lett. 9: 29-33.

21) Scher, F.M., J.W. Kloepper and C.A. Singleton. 1985. Chemotaxis of fluorescent Pseudomonas spp. to soybean seed exudates in vitro and in soil. Can. J. Microbiol. 31: 570-574.

22) Simons, M., A.J. van der Bil, I. Brand, L.A. de Weger, C.A. Wijffelman and B.J.J. Lugtenberg. 1996. Gnotobiotic system for studying rhizosphere colonization by plant growth-promoting Pseudomonas bacteria. Mol. Plant-Microbe Interact. 9: 600-607.

23) Simons, M., H.P. Permentier, L.A. de Weger, C.A. Wijffelman and B.J.J. Lugtenberg. 1997. Amino acid synthesis is necessary for tomato root colonization by Pseudomonas fluorescens strain WCS365. Mol. Plant-Microbe Interact. 10: 1021-106.

24) Streit, W.R., C.M. Joseph and D.A. Phillips. 1996. Biotin and other water-soluble vitamins are key growth factors for alfalfa root colonization by Rhizobium meliloti 1021. Mol. Plant-Microbe Interact. 9: 330-338.

25) Tari, P.H. and A.J. Anderson. 1988. Fusarium wilt suppression and agglutinability of Pseudomonas putida. Appl. Environ. Microbiol. 54: 2037-2041.

26) Toyota, K., K. Yamamoto and M. Kimura. 1994. Mechanisms of suppression of Fusarium oxysporum f. sp. raphani in soils so-called suppressive to Fusarium-wilt of radish. Soil Sci. Plant Nutr. 40: 373-380.

27) Toyota, K., K. Yamamoto and M. Kimura. 1994. Isolation and characterization of bacteria responsible for the suppression of Fusarium oxysporum $\mathrm{f}$. sp. raphani on the host rhizoplane. Soil Sci. Plant Nutr. 40: 381-390.

28) Toyota, K., T. Kamesaka and M. Kimura. 1995. The autecology of Fusarium oxysporum f. sp. raphani in soils suppressive and conducive to Fusarium-wilt of radish. FEMS Microbiol. Ecol. 
16: $261-268$.

29) Vesper, S.J. 1987. Production of pili (fimbriae) by Pseudomonas fluorescens and correlation with attachment to corn roots. Appl. Environ. Microbio1. 53: 1397-1403.

30) Weller, D.M. 1988. Biological control of soilborne plant pathogens in the rhizosphere with bacteria.
Ann. Rev. Phytopathol. 26: 379-407.

31) Weller, D.M. and L.S. Thomashow. Current challenges in introducing beneficial microorganisms into the rhizosphere. in "Molecular Ecology of Rhizosphere Microorganisms”, eds. by F. O'Gara, D.N. Dowling and B. Boesten. VCH, Weinheim, 1994, pp.1-18. 